Original Article

\title{
DEVELOPMENT AND VALIDATION OF STABILITY-INDICATING RP-UPLC METHOD FOR THE SIMULTANEOUS ESTIMATION OF TEZACAFTOR AND IVACAFTOR IN FORMULATIONS
}

\author{
S. LAKSHMI MANEKA ${ }^{*}$, R. T. SARAVANAKUMAR ${ }^{1}$, C. H. K. V. L. S. N. ANJANA ${ }^{2}$
}

1Department of Pharmacy, Annamalai University, Tamilnadu, India 608002, ${ }^{2}$ Department of Pharmaceutical Chemistry and Phytochemistry, Nirmala College of Pharmacy, Guntur, Andhra Pradesh 522503

Email: slmanu91@gmail.com

Received: 22 May 2020, Revised and Accepted: 30 Jul 2020

ABSTRACT

Objective: Aim of the present research work was to develop a sensitive, rapid and accurate, stability-indicating RP-UPLC method for the simultaneous estimation of tezacaftor and ivacaftor in formulations.

Methods: The chromatographic separation of the mixture of tezacaftor and ivacaftor was attained in isocratic method utilizing a mobile phase of $\mathbf{0 . 1}$ $\%$ orthophosphoric acid and acetonitrile in the proportion of $50: 50 \% \mathrm{v} / \mathrm{v}$ utilizing a HSS C18 column which has dimensions of $100 \times 2.1 \mathrm{~mm}, 1.7 \mu$ particle size and the flow rate of $0.3 \mathrm{ml} / \mathrm{min}$. The detection system was monitored at $292 \mathrm{~nm}$ wavelength maximum with $1.5 \mu \mathrm{l}$ injection volume. The present method was validated as per the guidelines given by the ICH for specificity, accuracy, sensitivity, linearity and precision.

Results: The retaining time for tezacaftor and ivacaftor were achieved at $1.071 \mathrm{~min}$ and 0.530 min, respectively. Tezacaftor, ivacaftor and their combined drug formulation were exposed to thermal, acidic, oxidative, photolytic, and alkaline conditions. The developed method was highly sensitive, rapid, precise and accurate than the earlier reported methods. The total run time was decreased to 2.0 min; hence, the technique was more precise and economical. Stability studies directed for the suitability of the technique for degradation studies of tezacaftor and ivacaftor.

Conclusion: The projected method can be utilized for routine analysis in the quality control department in pharmaceutical trades.

Keywords: Tezacaftor, Ivacaftor, RP-UPLC, Stability studies, Validation

(C) 2020 The Authors. Published by Innovare Academic Sciences Pvt Ltd. This is an open access article under the CC BY license (http://creativecommons.org/licenses/by/4.0/) DOI: http://dx.doi.org/10.22159/ijpps.2020v12i9.38412. Journal homepage: https://innovareacademics.in/journals/index.php/ijpps.

\section{INTRODUCTION}

Tezacaftor (TZR) and ivacaftor (IVR) drugs were combined in a single dosage form (tablet) in the brand name of symdeko, used to treat cystic fibrosis (CF) in patients more than six years old having genetically specific mutations. A wide variety of cystic fibrosis transmembrane regulator (CFTR) mutations correlate to the CFphenotype and are accompanied with different severity stages of the disease $[1,2]$. The most common mutation, affecting approximately $70 \%$ of patients with CF worldwide, is known as F508del-CFTR or delta-F508 ( $\Delta \mathrm{F} 508)$, in which a deletion in the amino acid phenylalanine at 508-position resulting in impaired production of protein CFTR, thereby producing a significant decrease in the quantity of ion transporter present on cell membranes. Ivacaftor as monotherapy has failed to show a benefit for patients with deltaF508 mutations, most likely due to an insufficient amount of protein available at the cell membrane for interaction and potentiation by the drug. CFTR correctors such as tezacaftor aim to repair F508del cellular misprocessing. This is done by modulating the position of the CFTR protein on the cell surface to the correct position, allowing for adequate ion channel formation and increased in water and salt movement through the cell membrane. The concomitant use of ivacaftor is intended to maintain an open channel, increasing the transport of chloride, reducing thick mucus production [3-5].

TZR chemically designated as 1-(2, 2-Difluoro-1, 3-benzodioxol-5-yl)- $N$ [1-[(2R)-2,3-dihydroxypropyl]-6-fluoro-2-(2-hydroxy-1, 1-dimethyl ethyl)- $1 H$-indol-5-yl]-cyclopropanecarboxamide with molecular weight of $520.505 \mathrm{~g} / \mathrm{mol}$. IVR chemically designated as $N$-(2, 4-Di-tert-butyl-5hydroxyphenyl)-4-oxo-1, 4-dihydroquinoline-3-carboxamide with molecular weight of $392.49 \mathrm{~g} / \mathrm{mol}$ (fig. 1) (Rowe and Verkman, 2012; Mohan, et al., 2017). The literature review discloses that a very few UPLC [6-8] and high performance liquid chromatographic techniques [9-13] have been reported for the estimation of TZR and IVR. Based on the reported HPLC methods, there is a need to develop a rapid, sensitive reversed-phase UPLC method for simultaneous estimation of TZR and IVR in bulk and formulations.
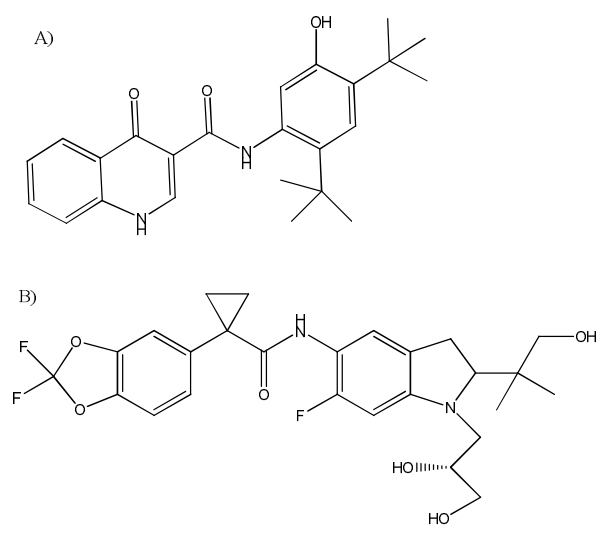

Fig. 1: Structures of A) ivacaftor and B) tezacaftor

\section{MATERIALS AND METHODS}

\section{Chemicals and reagents}

The standard components of TZR and IVR were provided as a gift sample from MSN Laboratories, Hyderabad, India. Symdeko tablets labeled to contain TZR $100 \mathrm{mg}$ and IVR $150 \mathrm{mg}$ were procured from the local market. HPLC grade acetonitrile was obtained from A. B enterprises, Mumbai, India. Orthophosphoric acid was bought from Ranchem, Mumbai, India. HPLC grade water was processed by utilizing Milli-Q Millipore water purification system used during the method development.

\section{Liquid chromatography}

Chromatographic system of Waters UPLC system furnished with photodiode array detector, auto-sampler, and HSS C18 column 
which have dimensions of $100 \times 2.1 \mathrm{~mm}, 1.7 \mu$ particle size. The output signal was monitored and integrated utilizing water Empower-2.0 software. The isocratic mobile consisting of $0.1 \%$ orthophosphoric acid and acetonitrile in the proportion of $50: 50 \% \mathrm{v} / \mathrm{v}$, pumped through the HSS C18 $(100 \times 2.1 \mathrm{~mm}, 1.7 \mu)$ column at a fixed flow of $0.3 \mathrm{ml} / \mathrm{min}$. The injection volume of $1.5 \mu \mathrm{l}$ was utilized to measure the chromatograms at $292 \mathrm{~nm}$ as the wavelength maximum in the detection system.

\section{Preparation of buffer}

To prepare $0.1 \%$ orthophosphoric acid buffer $1 \mathrm{ml}$ of orthophosphoric acid was diluted to $1000 \mathrm{ml}$ with HPLC grade water.

\section{Preparation of stock and standard solutions}

Accurately Weighed and transferred $25 \mathrm{mg}$ of TZR and $37.5 \mathrm{mg}$ of IVR working Standards into a $25 \mathrm{ml}$ clean dry volumetric flask, add $3 / 4^{\text {th }}$ volume of diluent (Water: ACN $(50: 50)$ ), sonicated for $5 \mathrm{~min}$ and made up to the final volume with diluent to get $1000 \mu \mathrm{g} / \mathrm{ml}$ of TZR and $1500 \mu \mathrm{g} / \mathrm{ml}$ of IVR (stock solution). $1 \mathrm{ml}$ of the resulting solution was transferred into a $10 \mathrm{ml}$ volumetric flask and made up to $10 \mathrm{ml}$ to get $100 \mu \mathrm{g} / \mathrm{ml}$ of TZR and $150 \mu \mathrm{g} / \mathrm{ml}$ of IVR.

\section{Preparation of sample solution}

20 tablets were weighed and calculated the average weight of tablets and then the weight equivalent to 1 tablet was transferred into a 100 $\mathrm{ml}$ volumetric flask containing $50 \mathrm{ml}$ of diluent and sonicated for $25.0 \mathrm{~min}$. Further, the volume made up with diluent and subjected for filtration by HPLC filters $(1000 \mu \mathrm{g} / \mathrm{ml}$ of TZR and $1500 \mu \mathrm{g} / \mathrm{ml}$ of IVR). From the filtrate $1.0 \mathrm{ml}$ solution was pipetted out into a 10.0 $\mathrm{ml}$ volumetric flask and made up to $10.0 \mathrm{ml}$ with diluent to get 100 $\mu \mathrm{g} / \mathrm{ml}$ of TZR and $150 \mu \mathrm{g} / \mathrm{ml}$.

\section{Analytical method validation}

The developed method for TZR and IVR was subjected for validation for the parameters like limit of detection (LOD), limit of quantification (LOQ), linearity, robustness, precision, system suitability and accuracy as per the guidelines of ICH [14-16].

\section{RESULTS AND DISCUSSION}

\section{Optimized chromatographic conditions}

After systematic trials with different mobile phase compositions and other parameters involved in the technique, HSS C18 100x $2.1 \mathrm{~mm}$ $1.7 \mu$ column, isocratic mobile consisting of $0.1 \%$ orthophosphoric acid and acetonitrile in the proportion of $50: 50 \% \mathrm{v} / \mathrm{v}$, column oven temperature of $30{ }^{\circ} \mathrm{C}$ with $1.5 \mathrm{ml}$ injection volume, $0.3 \mathrm{ml} / \mathrm{min}$ flow rate and detection wavelength of $292 \mathrm{~nm}$ were optimized. Water and acetonitrile in the ratio of 50:50 \% v/v was utilized as diluent.

\section{Specificity}

It is the ability of a method to unequivocally evaluate the analyte components in the presence of other components like impurities, degradants and excipients etc. expected to be present. This parameter was estimated by injecting and evaluating the blank, placebo, standard and sample solutions and chromatograms, respectively. Chromatograms of blank, placebo, and sample solution shown no peaks at the retaining time of TZR and IVR peaks. The chromatograms of TZR and IVR of standard, blank, formulation, and placebo were represented in fig. 2 .

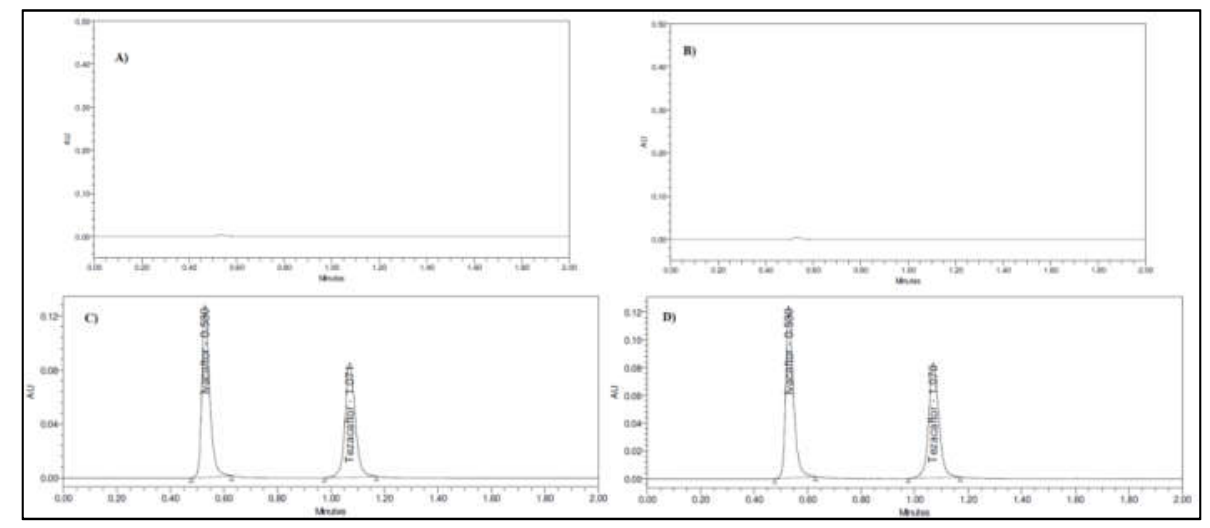

Fig. 2: Chromatograms of A) blank, B) placebo, C) standard and D) formulation

\section{Linearity}

Aliquots of $0.25,0.50,0.75,1.0,1.25$, and $1.50 \mathrm{ml}$ of standard stock solution were pipetted out from the standard stock solution of concentration $1000 \mu \mathrm{g} / \mathrm{ml}$ of TZR and $1500 \mu \mathrm{g} / \mathrm{ml}$ of IVR and made up to $10.0 \mathrm{ml}$ mark with diluent. The resulting solutions were come into 25 to $150 \mu \mathrm{g} / \mathrm{ml}$ of TZR and 37.5 to $225 \mu \mathrm{g} / \mathrm{ml}$ of IVR concentration range. The resulting linearity solutions were infused into a chromatographic system and form the chromatograms linearity graph was plotted by taking the peak area on Y-axis and concentration on X-axis. The calibration graphs were shown in fig. 3 , 4 and table 1 , and all findings were within limits.

Table 1: Calibration curve data of TZR and IVR

\begin{tabular}{llll}
\hline TZR & & IVR & Peak area \\
\hline Concentration $(\boldsymbol{\mu g} / \mathbf{m l})$ & Peak area & Concentration $(\boldsymbol{\mu g} / \mathbf{m l})$ & 81688 \\
\hline 25 & 58564 & 37.5 & 164210 \\
50 & 122099 & 75 & 245933 \\
75 & 182333 & 112.5 & 324531 \\
100 & 245412 & 150 & 403615 \\
125 & 298585 & 187.5 & 484784 \\
150 & 355250 & 225 \\
Regression equation & & \\
y=2384.4x+1488 & & $\mathrm{y}=2151 \mathrm{x}+1552.3$ \\
Correlation coefficient (R2) & & 0.9999 & \\
0.9994 & & \\
\hline
\end{tabular}




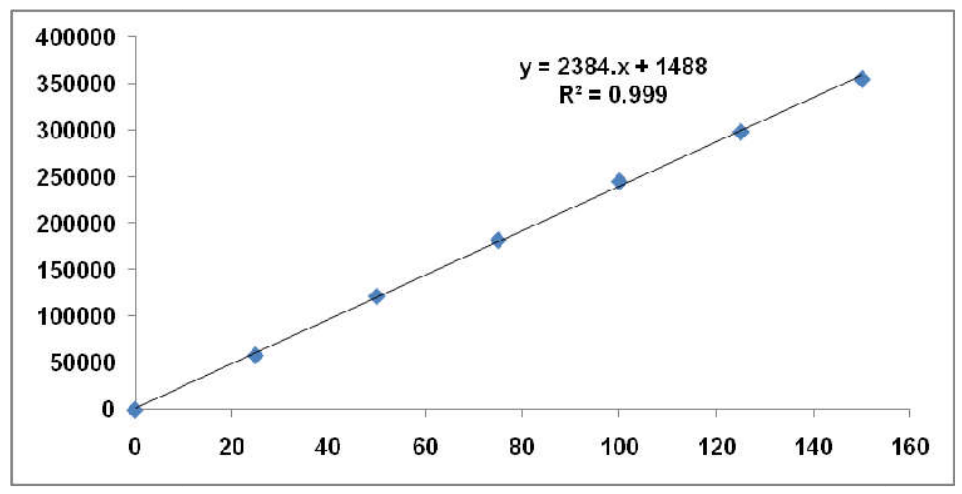

Fig. 3: Linearity of tezacaftor

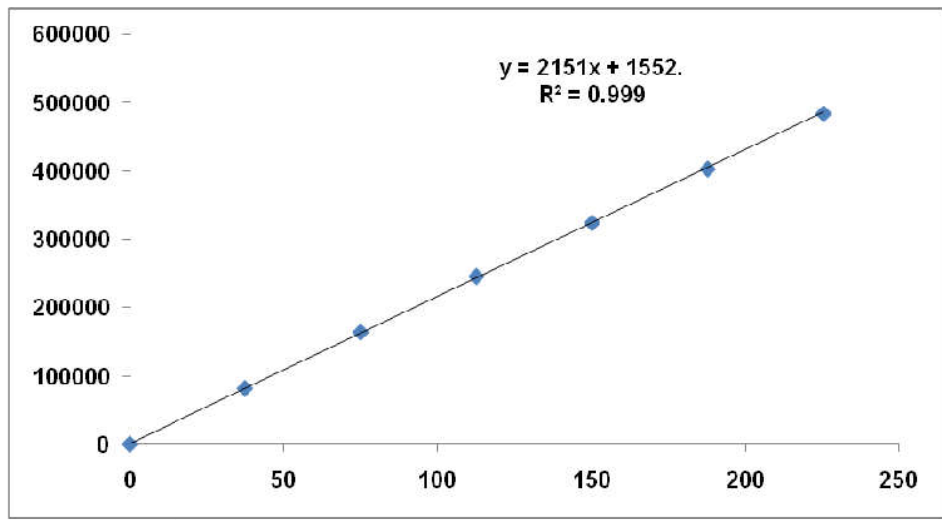

Fig. 4: Linearity of ivacaftor

\section{System suitability}

Six replicates of the standard reference solution were processed and infused to perform the system suitability parameter and the resulting chromatograms peak area, retention time, resolution, plate count, and tailing were measured. The findings of the system suitability parameter were shown in table 2 and related chromatograms were given in fig. 2(C)

Table 2: TZR and IVR system suitability results

\begin{tabular}{lllllll}
\hline S. No. & Peak name & Peak area & Retention time & Plate count & Resolution & Tailing \\
\hline 1 & IVR & 324491 & 0.531 & 2529 & 1.41 & 8.8 \\
2 & TZR & 245595 & 1.072 & 4351 & 1.08 & 8.8 \\
\hline
\end{tabular}

\section{LOD and LOQ}

LOD and LOQ parameters for TZR and IVR were calculated form the linear regression equation. Linearity values, graph and regression equation, were got from the linearity study and the LOD and LOQ values were represented in the table 3 .

\section{Precision}

Analytical method precision is defined as the closeness of agreement between the replicate measurements of the analyte. It is expressed as the percentage coefficient of correlation or relative standard deviation (RSD) of the replicate measurements.

\section{System precision}

Working standard preparation of $1.5 \mu$ l solution was infused six times into the chromatographic system and chromatograms were obtained. \%RSD of the peak area was calculated. The findings of system precision were shown in table 4.

\section{Method precision}

Working sample solutions of $1.5 \mu \mathrm{l}$ were infused 6 times into the chromatographic system and chromatograms were obtained. The $\%$ RSD of the assay result of six preparations was determined. The findings achieved for assay were represented in table 5 .

Table 3: Limit of detection and limit of quantification results

\begin{tabular}{lll}
\hline Parameter & Measured concentration $(\boldsymbol{\mu g} / \mathbf{m l})$ & \\
\cline { 2 - 3 } & TZR & IVR \\
\hline LOD & 0.41 & 0.47 \\
LOQ & 1.23 & 1.44 \\
\hline
\end{tabular}


Table 4: System precision data

\begin{tabular}{lll}
\hline S. No. & Peak area response of drugs & IVR \\
\cline { 2 - 3 } & TZR & 325617 \\
\hline 1 & 245595 & 329213 \\
2 & 246876 & 325596 \\
3. & 243399 & 324491 \\
4 & 247294 & 324384 \\
5 & 244267 & 326175 \\
6 & 244682 & 325913 \\
Average & 245304 & 1761.1 \\
STDV & 1522.7 & 0.5 \\
\% RSD & 0.6 & \\
\hline
\end{tabular}

STDV: Standard deviation; RSD: Relative Standard deviation

Table 5: Method precision results

\begin{tabular}{lll}
\hline S. No. & Peak area response of drugs & IVR \\
\cline { 2 - 3 } & TZR & 325135 \\
\hline 1 & 249019 & 330729 \\
2 & 243712 & 328369 \\
3. & 245330 & 323782 \\
4 & 243060 & 323587 \\
5 & 243574 & 323907 \\
6 & 244391 & 325918 \\
Average & 244848 & 2959.9 \\
STDV & 2188.6 & 0.9 \\
\hline
\end{tabular}

STDV: Standard deviation; RSD: Relative Standard deviation

Table 6: Intermediate precision results

\begin{tabular}{lll}
\hline S. No. & Peak area response of drugs & TZR \\
\cline { 2 - 3 } & IVR & 230390 \\
1 & 279082 & 232505 \\
2 & 278896 & 232781 \\
3. & 286045 & 235868 \\
4 & 282942 & 233126 \\
5 & 284263 & 232951 \\
6 & 286001 & 232937 \\
Average & 282872 & 1750.7 \\
STDV & 3224.0 & 0.8 \\
\hline
\end{tabular}

STDV: Standard deviation; RSD: Relative Standard deviation

Table 7: Percentage recovery results

\begin{tabular}{|c|c|c|c|c|c|c|c|c|}
\hline & IVR & & & & TZR & & & \\
\hline $\begin{array}{l}\text { Spiked } \\
\text { level }\end{array}$ & $\begin{array}{l}\text { spiked } \\
(\mu \mathrm{g} / \mathrm{ml})\end{array}$ & $\begin{array}{l}\text { recovery } \\
(\mu \mathrm{g} / \mathrm{ml})\end{array}$ & $\begin{array}{l}\text { \% } \\
\text { recovery }\end{array}$ & $\begin{array}{l}\text { Mean \% } \\
\text { recovery }\end{array}$ & $\begin{array}{l}\text { spiked } \\
(\mu \mathrm{g} / \mathrm{ml})\end{array}$ & $\begin{array}{l}\text { recovery } \\
(\mu \mathrm{g} / \mathrm{ml})\end{array}$ & \% recovery & $\begin{array}{l}\text { Mean \% } \\
\text { recovery }\end{array}$ \\
\hline \multirow[t]{3}{*}{$50 \%$} & 50 & 50.53892 & 101.08 & 100.21 & 75 & 74.90 & 99.87 & 99.97 \\
\hline & 50 & 50.04655 & 100.09 & & 75 & 74.55 & 99.40 & \\
\hline & 50 & 49.86412 & 99.73 & & 75 & 74.89 & 99.86 & \\
\hline \multirow[t]{3}{*}{$100 \%$} & 100 & 100.4525 & 100.45 & & 150 & 150.601 & 100.40 & \\
\hline & 100 & 101.0942 & 101.09 & & 150 & 150.1342 & 100.09 & \\
\hline & 100 & 100.3124 & 100.31 & & 150 & 148.3722 & 98.91 & \\
\hline \multirow[t]{3}{*}{$150 \%$} & 150 & 149.878 & 99.92 & & 225 & 227.7316 & 101.21 & \\
\hline & 150 & 149.6548 & 99.77 & & 225 & 225.3397 & 100.15 & \\
\hline & 150 & 149.2275 & 99.48 & & 225 & 224.5833 & 99.81 & \\
\hline
\end{tabular}

\section{Intermediate precision}

Working standard preparation of $1.5 \mu \mathrm{l}$ was infused six times test preparations into the chromatographic system and chromatograms were obtained. The \%RSD was evaluated for peak areas. The findings of intermediate precision study were represented in table 6 .

\section{Accuracy}

A known amount of IVR and TZR at each three concentration levels of $50 \%, 100 \%$, and $150 \%$ was added to a pre-analyzed sample solution and injected in triplicate at each level into the chromatographic system. The mean percentage recovery of IVR and TZR at each level was estimated. The findings were represented in tables 7 .

\section{Robustness}

Working standard solution prepared as per test method was infused into the chromatographic system at variable conditions such as flow rate at $\pm 0.1 \mathrm{ml} / \mathrm{min}$, mobile organic phase composition by $\pm 10 \%$, and column temperature by $\pm 5{ }^{\circ} \mathrm{C}$. The results of the robustness study parameter like peak area, retention time, plate count and tailing factor were within the limits.

\section{Forced degradation studies}

\section{Acid degradation studies}

To $1 \mathrm{ml}$ of stock s solution IVR and TZR, $1 \mathrm{ml}$ of $1 \mathrm{~N}$ Hydrochloric acid were added and refluxed for $30 \mathrm{~min}$ at $60^{\circ} \mathrm{C}$. The resultant solution 
was diluted to obtain $100 \mu \mathrm{g} / \mathrm{ml}$ of TZR and $150 \mu \mathrm{g} / \mathrm{ml}$ of IVR solution and $1.5 \mu \mathrm{l}$ solution was injected into the chromatographic system and the chromatograms were recorded to assess the stability of sample (fig. 5 and table 8 ) $[17,18]$.

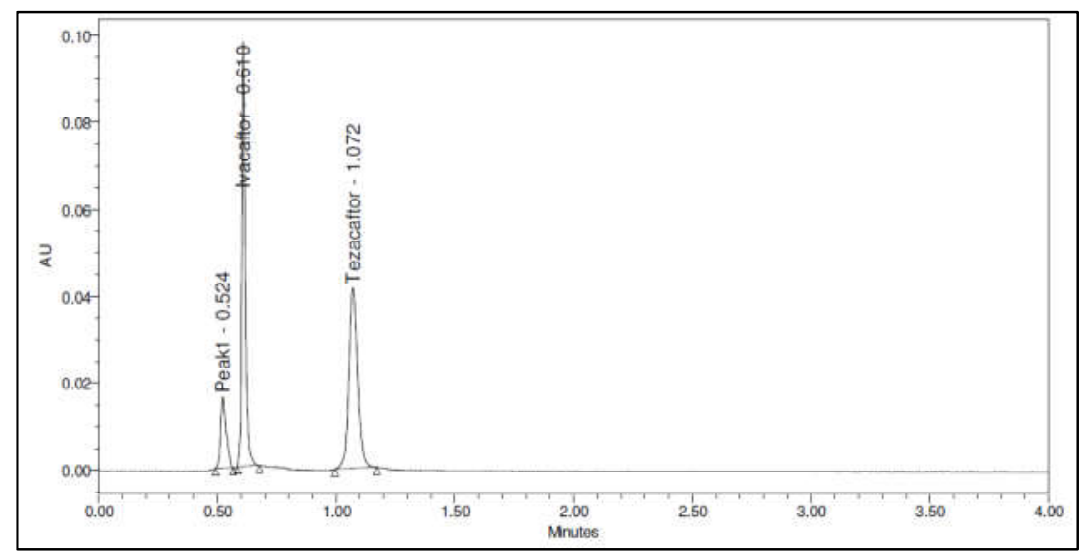

Fig. 5: Chromatogram for acid degradation study

Table 8: Results of stress degradation study

\begin{tabular}{llllll}
\hline \multirow{2}{*}{ S. No. } & Degradation condition & TZR & & IVR \\
\cline { 3 - 5 } & & \% recovery & \% Degraded & \% recovery \\
\hline 1 & Acid hydrolysis & 92.16 & 7.84 & 91.59 & \% Degraded \\
2 & Base hydrolysis & 93.56 & 6.44 & 92.82 & 7.41 \\
3 & Peroxide & 93.19 & 6.81 & 94.82 & 5.18 \\
4 & Dry heat & 97.98 & 2.02 & 96.60 & 3.40 \\
5 & Photostability & 98.46 & 1.54 & 97.88 & 2.12 \\
6 & Water sample & 99.51 & 0.49 & 99.14 & 0.86 \\
\hline
\end{tabular}

\section{Oxidation}

To $1 \mathrm{ml}$ of stock solution of VXR, SFR and VLR, $1 \mathrm{ml}$ of $10 \%$ hydrogen peroxide $\left(\mathrm{H}_{2} \mathrm{O}_{2}\right)$ was added separately. The solutions were kept for 30 $\min$ at $60^{\circ} \mathrm{C}$. For UPLC study, the resultant solution was diluted to obtain $100 \mu \mathrm{g} / \mathrm{ml}$ of TZR and $150 \mu \mathrm{g} / \mathrm{ml}$ of IVR solution and $1.5 \mu \mathrm{l}$ solution was injected into the chromatographic system and the chromatograms were recorded to assess the stability of sample (fig. 6 and table 8)

\section{Alkali degradation studies}

To $1 \mathrm{ml}$ of stock solution VXR, SFR and VLR, $1 \mathrm{ml}$ of $1 \mathrm{~N}$ sodium hydroxide were added and refluxed for $30 \mathrm{~min}$ at $60{ }^{\circ} \mathrm{C}$. The resultant solution was diluted to obtain $100 \mu \mathrm{g} / \mathrm{ml}$ of TZR and $150 \mu \mathrm{g} / \mathrm{ml}$ of IVR solution and $1.5 \mu \mathrm{l}$ solution was injected into the chromatographic system and the chromatograms were recorded to assess the stability of sample (fig. 7 and table 8) [18, 19].

\section{Dry heat degradation studies}

The standard drug solution was placed in an oven at $105^{\circ} \mathrm{C}$ for $6 \mathrm{~h}$ to study dry heat degradation [20]. For UPLC study, the resultant solution was diluted obtain $100 \mu \mathrm{g} / \mathrm{ml}$ of TZR and $150 \mu \mathrm{g} / \mathrm{ml}$ of IVR solution and $1.5 \mu \mathrm{l}$ solution was injected into the chromatographic system and the chromatograms were recorded to assess the stability of sample (fig. 8 and table 8 ).

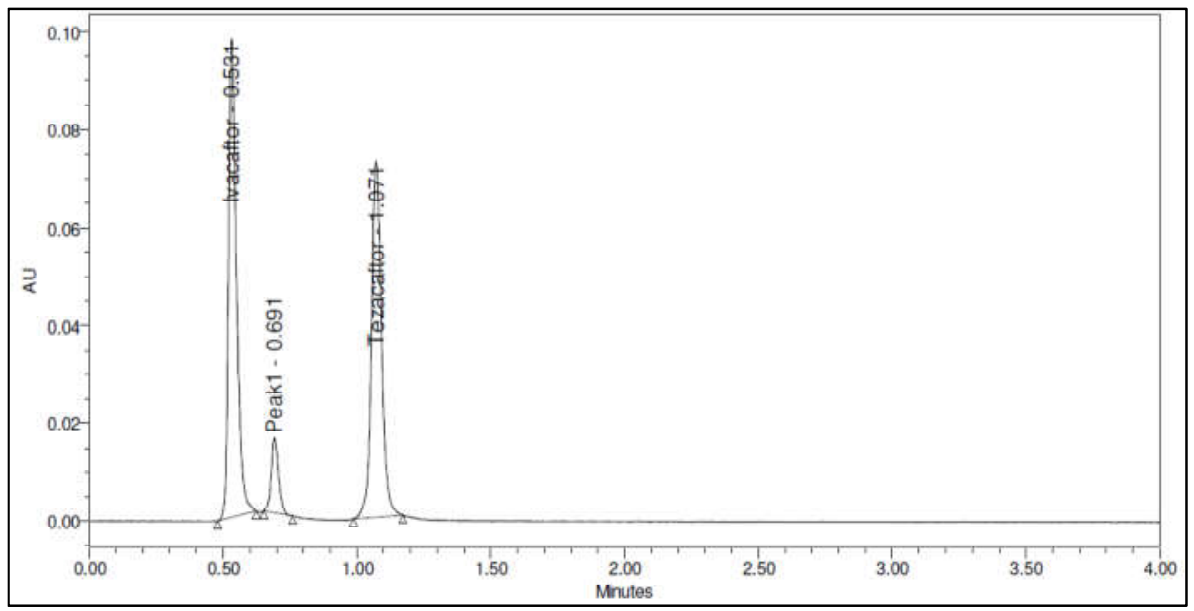

Fig. 6: Chromatogram for oxidation degradation study 


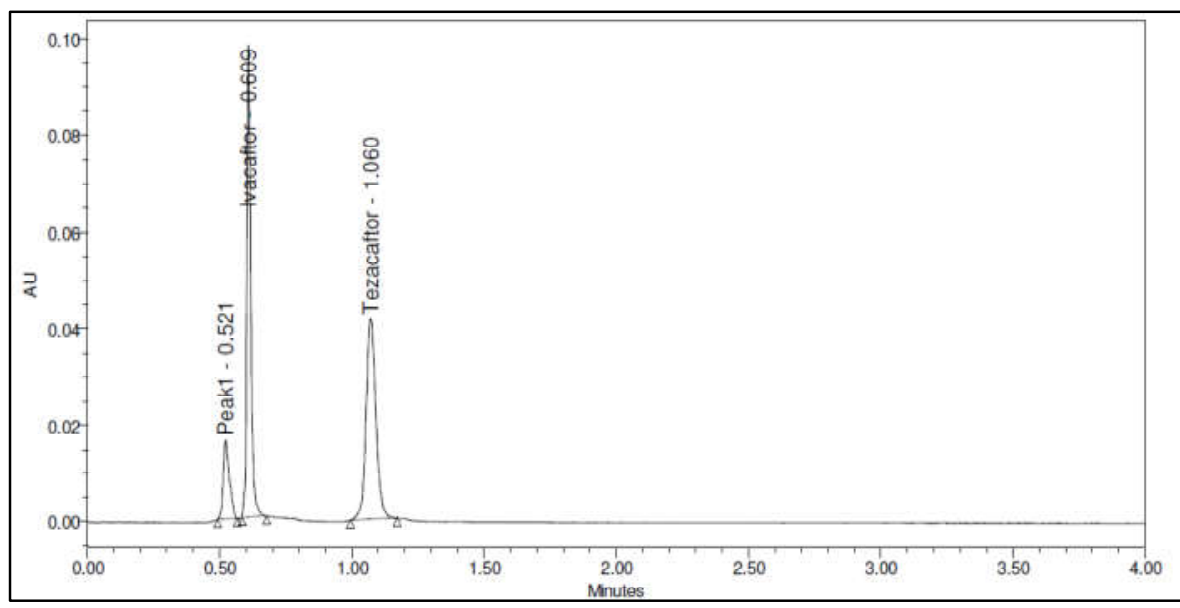

Fig. 7: Chromatogram for alkali degradation study

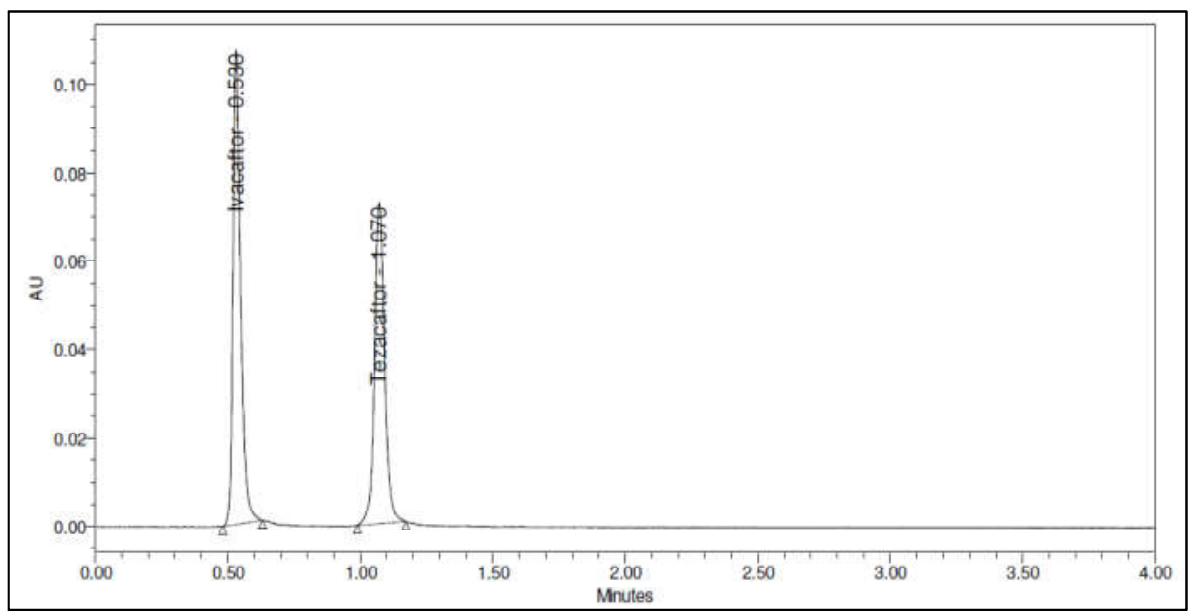

Fig. 8: Chromatogram for dry heat degradation study

\section{Photostability studies}

The photochemical stability of the drug was also studied by exposing the $(100 \mu \mathrm{g} / \mathrm{ml}, 400 \mu \mathrm{g} / \mathrm{ml}$ and $100 \mu \mathrm{g} / \mathrm{ml})$ solution to UV Light by keeping the beaker in UV Chamber for 7days or 200 Watt-hours $/ \mathrm{m} 2$ in photostability chamber [21]. For UPLC study, the resultant solution was diluted to obtain $100 \mu \mathrm{g} / \mathrm{ml}$ of TZR and $150 \mu \mathrm{g} / \mathrm{ml}$ of IVR solution and $1.5 \mu \mathrm{l}$ solution was injected into the chromatographic system and the chromatograms were recorded to assess the stability of sample (fig. 9 and table 8).

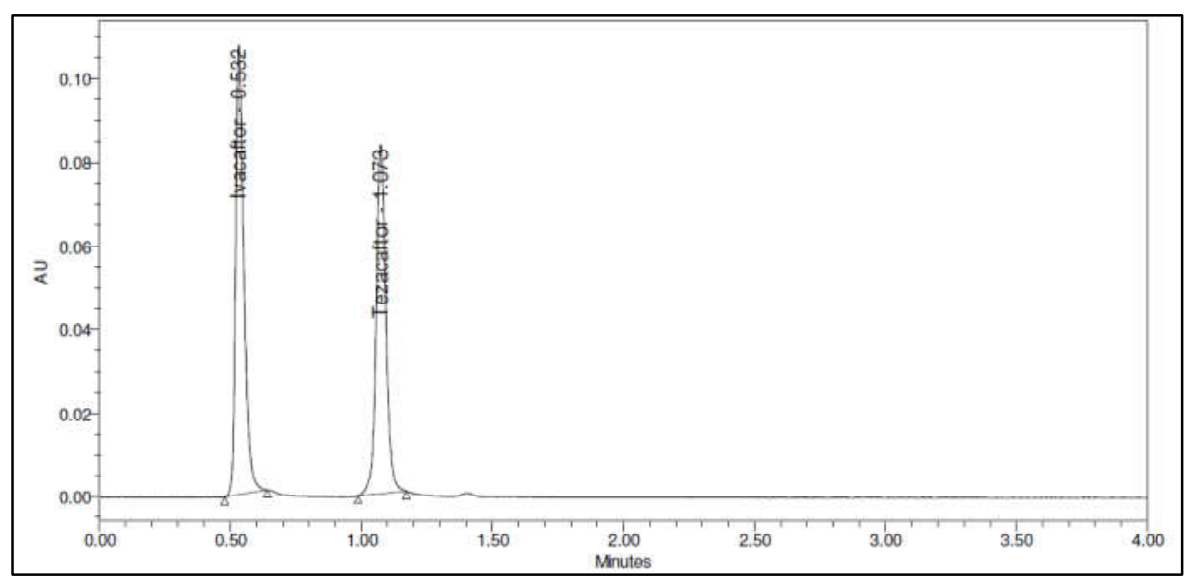

Fig. 9: Chromatogram for photostability study 


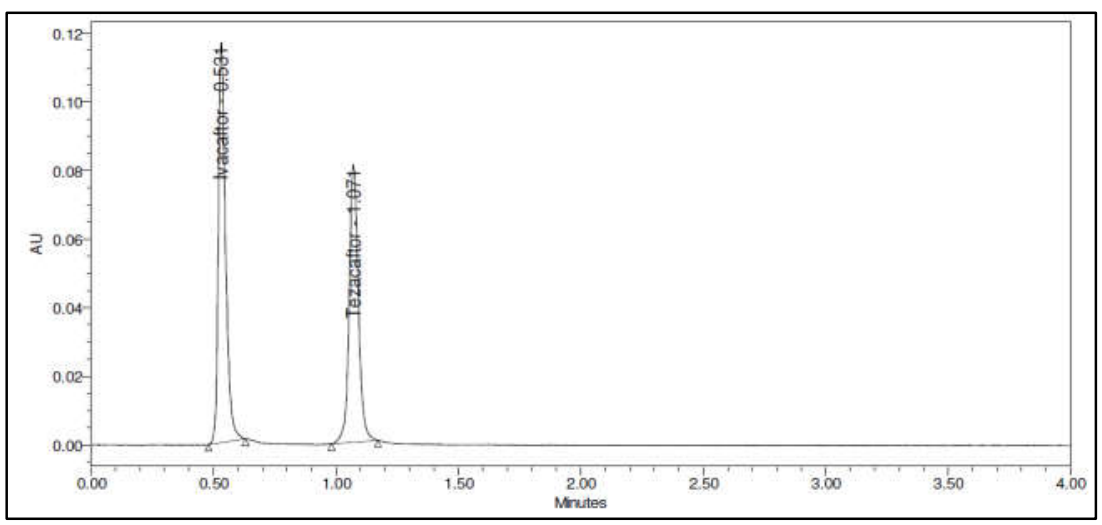

Fig. 10: Chromatogram for neutral degradation study

\section{Neutral degradation studies}

Stress testing under neutral conditions was studied by refluxing the drug in water for $6 \mathrm{~h}$ at a temperature of $60{ }^{\circ} \mathrm{C}$. For UPLC study, the resultant solution was diluted to obtain $100 \mu \mathrm{g} / \mathrm{ml}$ of TZR and $150 \mu \mathrm{g} / \mathrm{ml}$ of IVR solution and $1.5 \mu \mathrm{l}$ solution was injected into the chromatographic system and the chromatograms were recorded to assess the stability of sample (fig. 10 and table 8).

\section{Assay of marketed formulation}

The marketed formulation of Symdeko (tablet) was evaluated by infusing $1.5 \mu \mathrm{l}$ of reference and analyte solutions six times into the chromatographic system and the resulting chromatograms of analytes were documented [22]. The quantity of anaytes existed in the marketed formulation was estimated by equating the peak area of reference and analyte. The \% assay of TZR and IVR was found to be $99.0-101.0 \%$.

\section{CONCLUSION}

A sensitive, rapid and accurate, stability-indicating RP-UPLC method for the simultaneous estimation of TZR and IVR in formulations was developed and validated as per the ICH guidelines. Retention times for TZR and IVR were achieved at $1.071 \mathrm{~min}$ and $0.530 \mathrm{~min}$ respectively. Mean percentage recovery of TZR and IVR was found to be $100.21 \%$ and $99.97 \%$, respectively. LOD and LOQ values obtained from regression equations of TZR and IVR and were found to be 0.41 $\mu \mathrm{g} / \mathrm{ml} / 1.23 \mu \mathrm{g} / \mathrm{ml}$ and $0.47 \mu \mathrm{g} / \mathrm{ml} / 1.44 \mu \mathrm{g} / \mathrm{ml}$. Regression equation of TZR and IVR were: $\mathrm{y}=2384.4 \mathrm{x}+1488, \mathrm{y}=2151 \mathrm{x}+1552.3$ respectively. Stability studies of these drugs proven that the percentage of degradation of analytes were found in between $0.49 \%$ to $8.41 \%$. Retention time and total run times of analytes were decreased. Hence, the developed method was rapid and economical that can be applicable in routine analysis of these drugs in quality control department of pharmaceutical trades.

\section{FUNDING}

$\mathrm{Nil}$

\section{AUTHORS CONTRIBUTIONS}

Lakshmi Maneka performed experiments, analysed data and cowrote the paper. Anjana performed experiments. Saravanakumar designed and drafted the article.

\section{CONFLICTS OF INTERESTS}

The authors declare that there are no conflicts of interest regarding the publication of the paper.

\section{REFERENCES}

1. MacDonald KD, Mckenzie KR, Zeitlin PL. Cystic fibrosis transmembrane regulator protein mutations: 'class' opportunity for novel drug innovation. Paediatr Drugs 2007;9:1-10.
2. Yu H, Burton B, Huang CJ, Worley J, Cao D, Johnson JP Jr, et al. Ivacaftor potentiation of multiple CFTR channels with gating mutations. J Cyst Fibros 2012;11:237-45.

3. Flume PA, Liou TG, Borowitz DS, Li H, Yen K, Ordonez CL, et al. Ivacaftor in subjects with cystic fibrosis who are homozygous for the F508del-CFTR mutation. Chest 2012;142:718-24.

4. Rowe SM, Verkman AS. Cystic fibrosis transmembrane regulator correctors and potentiators. Cold Spring Harb Perspect Med 2013;3:174.

5. Fohner AE, McDonagh EM, Clancy JP, Whirl Carrillo M, Altman RB, Klein TE. PharmGKB summary: ivacaftor pathway, pharmacokinetics/pharmacodynamics. Pharmacogenet Genomics 2017;27:39-42.

6. Shyamala, Dongamanti Ashok. A novel stability indicating UPLC method for the estimation of tezacaftor and ivacaftor in tablet dosage form. Int J Pharm Sci Res 2019;10:4968-73.

7. Balaswami B, Ramana PV, Rao BS, Sanjeeva P. A new simple stability indicating RP-HPLC-PDA method for simultaneous estimation of triplicate mixture of sofosbuvir, voxilaprevir and velpatasvir in tablet dosage form. Res J Pharm Technol 2018;11:4147-56.

8. Baki Sharon, Meruva Sathish Kumar, Marakatham S, Kanduri Valli Kumari. A new RP-UPLC method development and validation for the simultaneous estimation of ivacaftor and lumacaftor. J Global Trends Pharm Sci 2018;9:5730-7.

9. Dastagiri J, Sivagami B, Pavan Kumar V, Hemalatha S, Gunasekar G. Stability indicating RP-HPLC method for simultaneous estimation of lumacaftor and ivacaftor in bulk and pharmaceutical dosage form. J Pharm Sci Res 2019;11:2898-904.

10. Mohan Goud V, Sharma JVC, Sravanthi M. Stability indicating ultra-performance liquid chromatography method development and validation for simultaneous estimation of ivacaftor and tezacaftor in bulk and pharmaceutical dosage form. Int J Sci Res Rev 2019;8:128-32.

11. Srimounika Gadeela, Shyamala, Sharma JVC, Swarupa A. A new stability-indicating method for simultaneous estimation of ivacaftor and tezacaftor by RP-HPLC in bulk and its dosage form. Int I Res Anal Rev 2018;5:774-85.

12. Akram NMD, Umamahesh M. A new validated RP-HPLC method for the determination of lumacaftor and ivacaftor in its bulk and pharmaceutical dosage forms. Oriental J Chem 2017;33:1492-501.

13. Balaswami B, Venkata Ramana P. A new stability-indicating RPUPLC method development and validation for the simultaneous estimation of ivacaftor and tezacaftor in the pharmaceutical dosage form. Int J Pharm Biol Sci 2019;9:1158-66.

14. Anjaneyulu Reddy B, Irshad Alam MD, Nazia Khanam, Radha Krishnanand P. An innovative method development and forced degradation studies for simultaneous estimation of sofosbuvir and ledipasvir by RP HPLC. Int J Pharm Pharm Sci 2019;11:1-8.

15. ICH: Q2 (R1), Validation of analytical procedures: text and methodology; 2005.

16. ICH: Q2B. Harmonized Tripartite Guideline, Validation of Analytical Procedure: Methodology, IFPMA, in: Proceedings of the International Conference on Harmonization, Geneva; 1996. 
17. ICH Guidelines Q1A (R2), Stability Testing of New Drug Substances and Products, International Conference on Harmonization; 2003.

18. Ngwa G. Forced degradation studies as an integral part of HPLC stability-indicating method development. Drug Delivery Technol 2010;10:56-9.

19. Sravanthi B, Divya M. Analytical method development and validation of ivacaftor and lumacaftor by RP-HPLC method, Indo Am. J Pharm Sci 2016;3:61-8.

20. Ashwini R Bharati, Subhash V Deshmane, Kailsh R Biyani. Stability indicating RP-HPLC method development and validation for simultaneous estimation of amlodipine and hydrochlorothiazide in pharmaceutical dosage form. Int J Curr Pharm Res 2014;7:79-82

21. Mitali Verma V, Chirag J Patel, Patel MM. Development and stability-indicating HPLC method for dapagliflozin in api and pharmaceutical dosage form. Int J Appl Pharm 2017;9:33-41.

22. Swetha A, Ramya Kuber B. Stability-indicating reverse-phase high-performance liquid chromatographic method development for simultaneous estimation of sofosbuvir and daclatasvir in pure and pharmaceutical formulation. Asian J Pharm Clin Res 2019:12:56-63. 